\title{
ПЕРСПЕКТИВЫ ИСПОЛЬЗОВАНИЯ ЭЛАСТОМЕРНЫХ НОСИТЕЛЕЙ ЗАПИСИ ДЛЯ ОТОБРАЖЕНИЯ ИНФОРМАЦИИ НА ОСНОВЕ МОЭМС-ТЕХНОЛОГИИ
}

\author{
А. П. Маняк \\ АЛЕКСЕЙ ПАВЛОВИЧ МАНЯК - аспирант кафедры оптико-электронных приборов и систем РТУ \\ МИРЭА.E-mail: manyak@mirea.ru. \\ 119454, г. Москва, Проспект Вернадского, д. 78, ФГБОУ ВО «МИРЭА - Российский технологический \\ университет» (РТУ МИРЭА).
}

В данной работе рассмотрены перспективы разработки фазовых рельефографических модуляторов света на основе микрооптических электромеханических систем для отображения информации в проекционных системах. В основе модулятора за основу взят рельефографический эластомерный носитель записи. Рассмотрены приниипы формирования записи на геле-носителе и его основные характеристики. Приведен пример реализачии проекционной системы на базе разрабатываемого модулятора.

Ключевые слова: модулятор света, рельефография, эластомерный носитель записи.

\section{PROSPECTS FOR USING ELASTOMERIC CARRIERS FOR DISPLAYING INFORMATION BASED ON MEMS TECHNOLOGY}

\begin{abstract}
A.P. Manyak
78, Vernadsky Avenue, 119454, Moscow, Russia. Department of Optoelectronic Devices and Systems, MIREARussian Technological University (RTU - MIREA).
\end{abstract}

This paper discusses the prospects for developing phase reliefographic light modulators based on microoptical electro-mechanical systems for displaying information in projection systems. The modulator is based on a reliefography elastomeric carrier. The principles of forming a record on a gel carrier and its main characteristics are considered. An example of implementing a projection system based on the modulator being developed is given.

Keywords: modulator light, reliefography, elastomeric carriers.

\section{Введение}

МОЭМС расшифровывается, как микрооптические электромеханические системы (MicroOptical-ElectroMechanical Systems, MOEMS). Данная технология позволяет создавать миниатюризированные механические и оптические структуры и интегрировать их в электронные схемы. Глав- ный принцип работы таких систем заключается в управлении деформацией среды посредством электрических сигналов. В отличие от обычных МЭМС, в МОЭМС стоит задача работы с оптическим сигналом. Таким образом, на основе данной технологии могут быть изготовлены различные оптические компоненты и оптико-электронные устройства, и системы, которые могут изменять, 
модулировать путь светового луча или спектрально модифицировать световой луч. [1]

На данный момент из наиболее известных устройств отображения информации, выполненных по технологии МОЭМС, выделяют [1]:

1) Дисплеи компании Qualcomm, выполненные по технологии интерферометрической модуляции IMOD (Interferometric MODulation);

2) DMD (Digital Mirror Devices)-дисплеи компании Texas Instruments, которые представляют собой матрицу из микрозеркал на полупроводниковом чипе и управляемые по технологии DLP (Digital Light Processing);

3) Модули GLV (Grating Light Valve) компании Silicon Light Machines, представляющие coбой динамически настраиваемые дифракционные решетки, состоящие из последовательности избирательно деформируемых тонких микроскопических металлизированных кремниевых подвесных полосок;

4) одиночные сканирующие микрозеркала компании Microvision и Maradin Technologies, Ltd;

5) двойные сканирующие микрозеркала комании bTendo, Ltd.

Причем DMD дисплеи достигли достаточно высокого коммерческого уровня и уже сейчас широко используются в современных проекторах высокого разрешения и составляют серьезную конкуренцию технологии жидких кристаллов на кремнии (Liquid Crystal on Silicon, LCoS) и экранам на основе жидких кристаллов (LCD- liquid crystal display).

Составить же конкуренцию представленным выше устройствам отображения информации могут рельефграфические модуляторы света, принцип действия которых основан на изменении поверхности носителя записи под действием внешних электрических полей.

Лаборатория наноэлектрооптики кафедры оптико-электронных приборов и систем Физико-технологического института РТУ МИРЭА предлагает использовать разработанный в ней оригинальный фазовый рельефографический модулятор све- та «Рельеф» (Light modulator Relief -LMR), в котором используется эластомерный носитель записи.

\section{Рельефографические модуляторы света (РМС)}

В основе РМС лежит принцип рельефографии. Впервые данный принцип был предложен Ф. Фишером в 1939 г. В нашей стране исследования по физике рельефографии были продолжены и развиты д.т.н. Гущо Ю.П.

В работе [2] дается определение рельефографии как метода накопления и представления информации в виде рельефа, воспроизводят которую преобразованием в амплитудные фазовые изменения считывающего излучения.

Информация записывается в виде изменении формы (рельефа) поверхности на специальном прозрачном (отражающем) диэлектрическом слое, называемом носителем записи. В качестве носителя записи используют жидкие (масляные), эластомерные, термаплостические и мембранные деформируемые слои.

Излучение, падающее на такую рельефную поверхность вследствие рефракции или дифракции света, меняет направление или фазу. Фазовые же изменения излучения нельзя будет обнаружить невооруженным глазом или обычными средствами восприятия. Поэтому для воспроизведения информации (к примеру, видеопотока) с носителя применяются методы преобразования фазовой модуляции считывающего излучения в амплитудные (к примеру, шлирен-метод).

Рельефографический прибор отображения информации будет состоять из рельефо-фазового носителя записи, устройства ввода записи, устройства преобразования записи в амплитудный сигнал и устройства восприятия информации.

Рассмотрим принцип записи и стирания информации на эластомерном носителе записи (рис. 1).

Система работает как воздушный конденсатор, в качестве одной из обкладок которого служит эластомерный носитель записи 4 , нанесенный
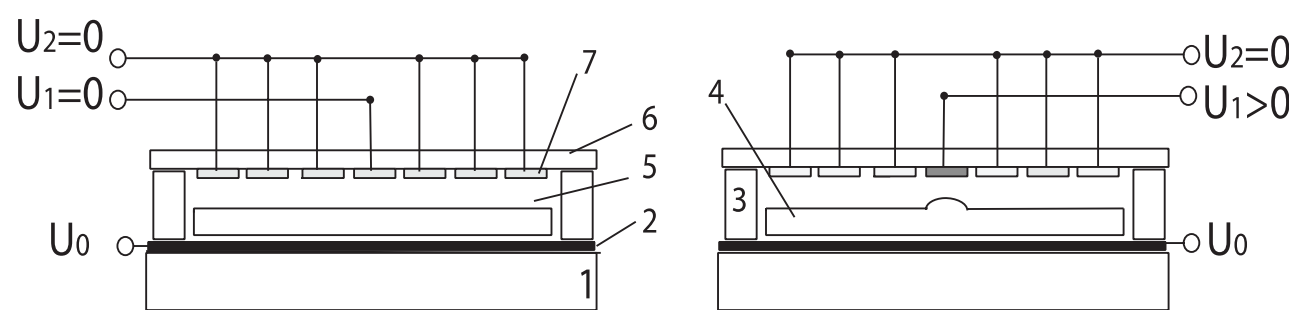

Рис. 1. Запись и стирании информации в РМС

1 - стеклянная подложка; 2 - проводящий слой; 3 - спейсер; 4 - эластомерный носитель записи; 5 - воздушный зазор; 6 - подложка с электродами; 7 - электроды 

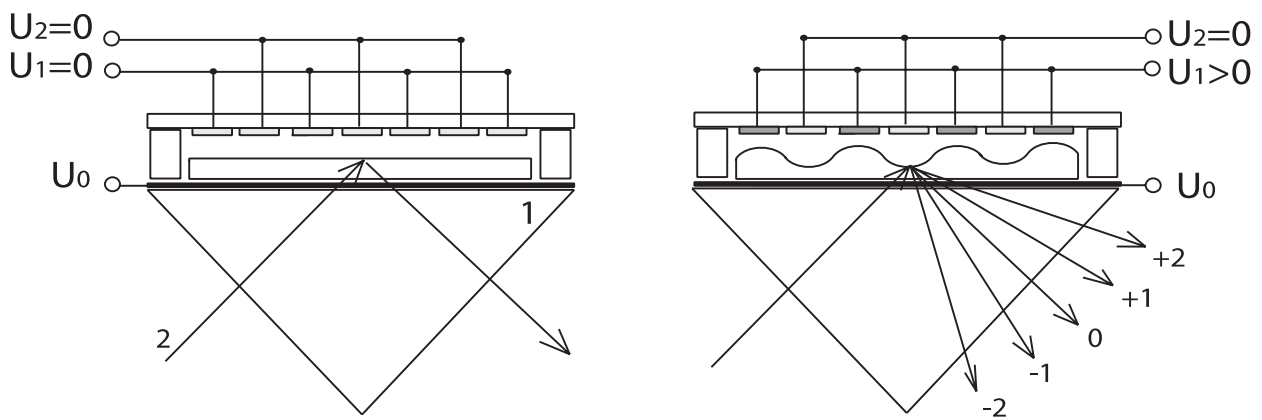

Рис. 2. Призматический РМС. Пример формирования дифракционной решетки 1 - призма полного внутреннего отражения; 2 -луч света

на стеклянную подложку 1 с проводящим слоем 2 , а другой - металлический электрод 7.

При подаче сигнала $\left(\mathrm{U}_{1}>0\right)$ между электродом и проводящим слоем на подложке возникает неоднородное электрическое поле и соответствующее ему распределение пондеромоторных сил. Под действием этих сил возникает рельеф на поверхности эластомерного слоя. Процесс образования и стирания рельефа будет зависеть от диэлектрических, геометрических и других параметров РМС.

На рис. 2 показан вариант РМС с применением призмы полного внутреннего отражения, с помощью которой можно избежать оптические шумы на поверхности электродов управления 7. В этом случае свет отражается от деформируемой свободной поверхности носителя и не попадает на электроды управления.

Пока напряжение $\left(\mathrm{U}_{1}=0, \mathrm{U}_{2}=0\right)$ на электродах отсутствует, гелеобразный слой не меняет свой рельеф (плоский) и все падающие лучи отражаются от него как от плоского зеркала. Когда подается управляющий сигнал $\left(\mathrm{U}_{1}>0, \mathrm{U}_{2}=0\right)$, образуется периодическая решетка на гелеобразном слое (создается рельеф).

Таким образом, РМС в оптическом плане является управляемой фазовой дифракционной решеткой. Время записи (образования) и стирания (исчезновения) такого нанорельефа составляет единицы микросекунд. Упругие наноперемещения активного поверхностного слоя обеспечивают уникальное быстродействие и низкую инерционность модулятора в широком диапазоне температур. Отсутствие подвижных частей и малое энергопотребление, позволяют разработать компактные варианты данного модулятора с низкой себестоимостью в массовом производстве.

Основные характеристики модулятора света представлены в табл. 1.

Особо важно подчеркнуть, что рельефографический модулятор света обеспечивает высокий КПД пропускания, так как практически не поглощает световую энергию, которая проходит
Таблииа 1

Характеристики РМС «Рельеф»

\begin{tabular}{cc}
\hline Параметры & Значения \\
\hline Частота переключения пикселя, МГц & 0,4 \\
\hline Рабочий температурный диапазон, ${ }^{\circ} \mathrm{C}$ & $-5 \div+80$ \\
\hline Дифракционная эффективность, $\%$ & 98,6 \\
\hline $\begin{array}{c}\text { Высокое сопротивление к лазерному } \\
\text { излучению, Вт }\end{array}$ & до 100 \\
\hline
\end{tabular}

Не требуется поляризация света

Малое рассеяние света

Дифракционная оптика с фильтрацией шума

Объёмное отображение информации

Диапазон светового излучения от 0,5 до 25 мкм

через него. Излучение только меняет направление, без потери мощности.

Уникальные характеристики РМС открывают возможности применения в различных устройствах электрооптических систем. В работах [3-5] приведены различные примеры применения данного модулятора (в частности, проецирования изображения, коррекции волнового фронта, сканирования пространства, подавления спекл-шума, лазерные источники света 4-го поколения с рельефографическим спеклоподавителем). Одним из перспективных направлений применения данного модулятора может послужить создание полноцветного голографического телевизора [6].

\section{Эластомерный носитель записи}

Роль основного элемента в РМС играет специальный прозрачный тонкий деформируемый диэлектрический слой - гелеобразный носитель записи. Носитель записи имеет следующие свойства:

1. Высокий коэффициент пропускания в рабочей спектральной области. 
2. Высокое оптическое качество поверхности.

3. Показатель преломления равен показателю преломления стеклянной подложки.

4. Высокая эластичность. При работе носитель меняет свою форму поверхности, что приводит к образованию рельефа.

5. Физическая стабильность. Носитель должен иметь относительно высокую температуру плавления, не менять своих свойств при изменении влажности и температуры в широких пределах.

6. Химическая совместимость. Носитель не должен реагировать с воздухом, либо проводящим слоем, менять свою адгезию к подложке.

Благодаря достаточно широкому диапазону компонентов для приготовления носителя записи, можно создавать образцы различного быстродействия и чувствительности к электрическому сигналу. Возможны комбинации, когда быстродействие и чувствительность заданы теми или иными техническими условиями одновременно. За счет оптимальной комбинации компонентов, полимерный гель для РМС пропускает до 95 \% излучения в диапазоне от видимой области спектра до ИК-области с длинами волн вплоть до 25 мкм с небольшим провалом на длине волны 2,5 мкм (рис. 3).

Для получения объективной оценки параметров рельефографического фазового модулятора, необходимо исследовать рельефографический носитель записи, но его теоретический расчёт крайне сложен, т.к. вязкость, упругость и электрическое сопротивление зависят от методики изготовления и состава компонентов этого образца, поэ- тому необходимо экспериментальное исследование отклика носителя на заданное электрическое воздействие. Для проведения такого исследования был собран лабораторный стенд зондовой измерительной установки, принцип работы которого описан в работе [7].

Отклик носителя при воздействии на него управляющего сигнала представлен на рис. 4.

Получив отклик носителя записи и определив по переходным характеристиками постоянные времени механической и электрической релаксации, можно вычислить необходимые параметры носителя.

\section{Устройство отображения информации}

Для воспроизведения информации с носителя записи необходимо реализовать систему по преобразованию фазовых изменений света в амплитудные. Такая система воспроизведения представляет собой шлирен-проектор [2].

На рис. 5 представлена принципиальная схема реализации лабораторного проектора с призматическим РМС [4].

Суть работы проектора заключается в следующем: свет от источника 1 проходит РМС 5 и фокусируется с помощью объектива 6 в фазовой плоскости на диафрагме (пространственном фильтре 7). Экран в этом случае остаётся темным. На экране появляется изображение, если под действием электрического сигнала возникает нанорельеф на носи-

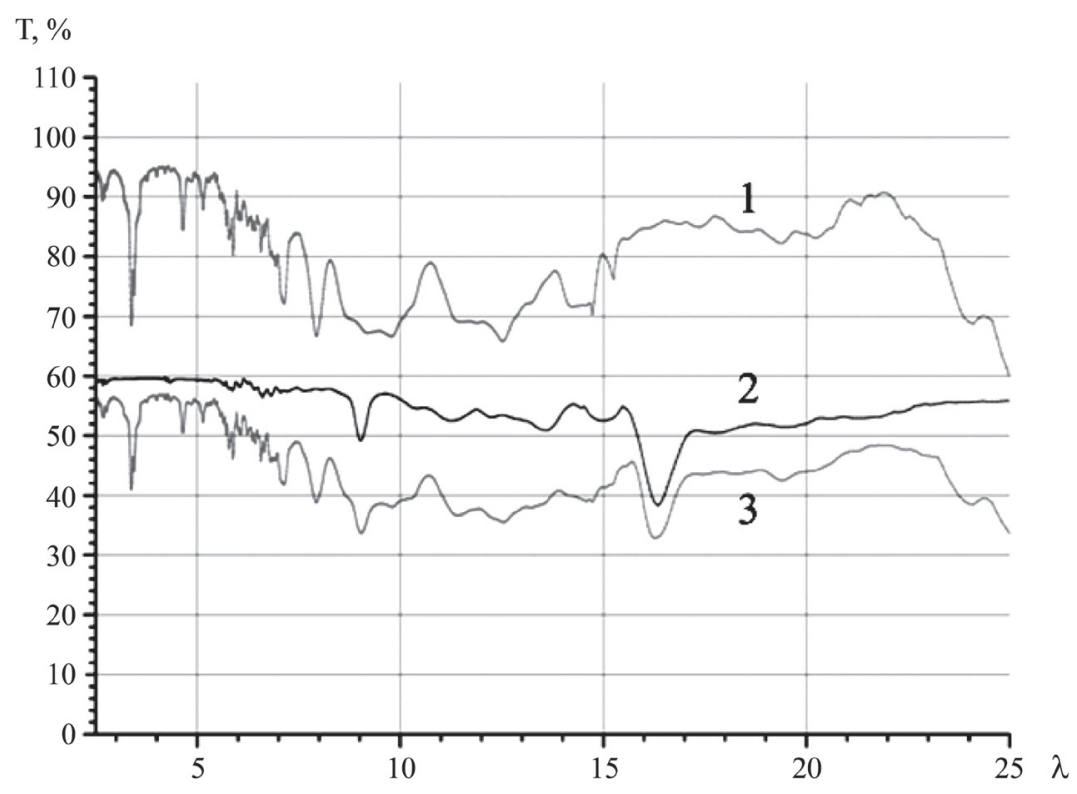

Рис. 3. График светопропускания [5]

$T$ - коэффициент пропускания, $\boldsymbol{\lambda}$ - длина волны излучения, в мкм;

1 - пленка (образеи толщиной 20 мкм); 2 - кремний; 3 - кремний с пленкой 


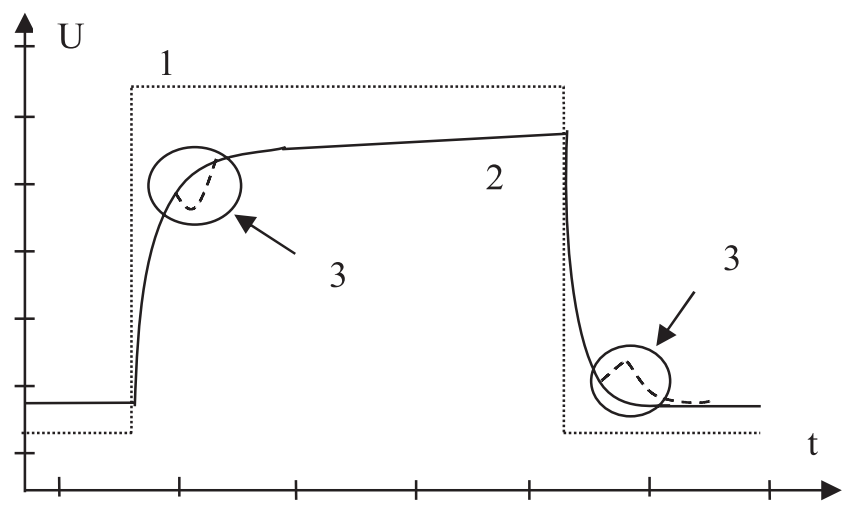

Рис. 4. График отклика носителя записи на прикладываемое управляемое напряжение

1 - прикладьваемое управляемое напряжение на электрод в виде прямоугольного сигнала;

2 - идеальный график отклика носителя на управляемое напряжение; 3 - составляющие переходного процесса в реальном отклике системь

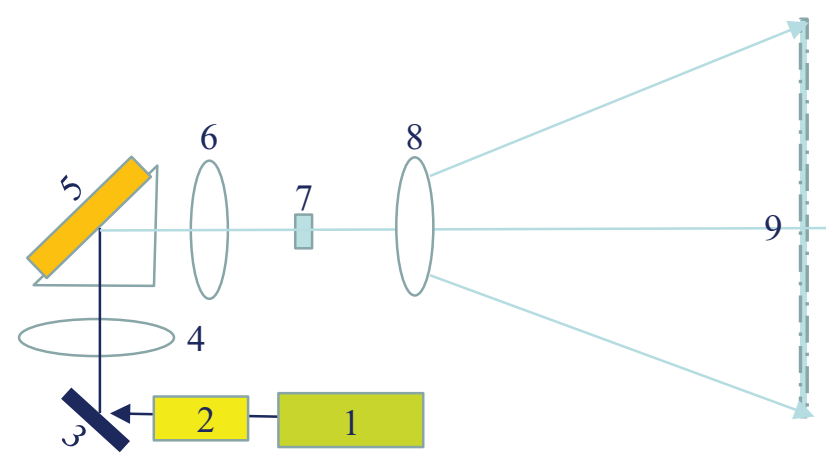

Рис. 5. Принципиальная схема лабораторного проектора с призматическим РМС

1 -источник света; 2 - фильтр; 3 - зеркало; 4 - осветительный объектив; 5 - призматический РМС; 6-Фурье объектив; 7- пространственньй фильтр; 8 - проекционный объектив; 9 - экран

теле РМС, который изменяет фазовые характеристики считывающего излучения. [4]

В настоящее время лабораторный образец модулятора имеет габариты $180 \times 200 \times 200$ мм³ $^{3}$ разрешение $512 \times 384$ пикселей; выходной световой поток 50 лм и сфероцилиндрическую оптику. [4]

\section{Заключение}

Рассмотрев все вышеизложенные аспекты, можно сделать вывод, что технология РМС «Рельеф» обладает следующими преимуществами:

1. Малое время записи/стирания рельефа.
2. Отсутствие механических подвижных частей.

3. Использование твердотельного полимера, что повышает стабильность в широком диапазоне рабочих температур и давлений.

4. Возможность масштабирования.

5. Малое энергопотребление.

6. Низкая себестоимость при массовом производстве.

Основным минусом данной технологии считается необходимость обеспечения чистого производственного процесса, так как в дифракционной оптике любые неоднородности критичны. Таким образом, технология РМС «Рельеф» может считаться крайне эффективной и оптимальной для развития на ее основе устройств отображения информации.

\section{Литература}

1. Сысоева C. HUD: Проекция будущего. Компоненты и технологии, №10(135), 2012, с. 92-102.

2. Гущо Ю.П. Физика рельефографии. М.: Наука, 1999. $524 \mathrm{c}$.

3. Гущо Ю.П., Гущо М.А., Бурага А.В. Фазовый модулятор света «Рельеф» и его применения. Международная научно-техническая конференция «информатика и технологии. Инновационные технологии в промышленности и информатике» («МНТК ФТИ2017)». Сборник научных трудов. Под редакцией Булатова М.Ф. 2017. С. 600-603.

4. К Кузнецов В.В., Гущзо Ю.П., Гущо М.А. Портативный лазерный пикопроектор. Технологии и материалы для экстремальных условий (лазерные технологии, источники тока и материалы): материалы 12-й Всероссийской конференции (Туапсе, 11-15 сентября 2017 г.). - М.: МЦАИ РАН, 2017. С. 16-22.

5. Гущо М.А., Гущо Ю.П., Кузнеиов В.В. Семейство лидаров на перестраиваемых дифракционных решетках. Сборник докладов научно-технической конференции с международным участием «Оптические технологии, материалы и системы (ОПТОTEX-2017)». Физико-технологический институт, Московский технологический университет (МИРЭА), Москва, 14-15 декабря 2017 г. С. 110-115.

6. Гущзо Ю.П., Кузнещзов В.В. От дифракционной решетки к голографическому телевидению. Юбилейный Всероссийский форум научной молодежи «Шаг в будущее»: Доклады пленарных заседаний. - М.: РОО НТА АПФН. 2016. С. 45-54.

7. Богданов В.С., Зивенко Н.О., Маняк А.П. Лабораторный стенд по снятию характеристик рельефографического эластомерного носителя записи. Тезисы докладов IX научно-практической конференции молодых ученых и специалистов «Фотосенсорика: новые материалы, технологии, приборы, производство». - М.: АО «НПО «Орион». 2020. С. 50-52. 